\title{
THE PENETRATION OF ENGINEERING BY ECONOMICS: MCFADDEN (1974) AND THE TRANSFORMATION OF ROAD DEMAND ESTIMATION ${ }^{1}$
}

\author{
Ariane Dupont-Kieffer \\ (PHARE, University Paris 1$)^{2}$ \\ Sylvie Rivot \\ (BETA, University of Haute-Alsace) ${ }^{3}$ \\ Jean-Loup Madre \\ (AME, DEST, Ifsttar) ${ }^{4}$
}

\section{ABSTRACT}

The golden age of road demand modeling began in the 1950s and flourished in the 1960s in the face of major road construction needs. These macro-models as well as the econometrics and the data to be processed, were mainly provided by engineers. A division of tasks can be observed between the engineers in charge of estimating the flows within the network, and the transport economists in charge of managing these flows once they are on the road network. Yet the inability to explain their decision-making processes and individual drives gave some room to economists to introduce economic analysis, so as to better understand individual or collective decisions between transport alternatives. Economists, in particular McFadden, began to offer methods to improve the measure of utility linked to transport, and to inform the engineering approach. This paper explores the challenges to the boundaries between economics and engineering in road demand analysis.

JEL: B23, B31, L6, R4

1 This paper was first presented at the Charles Gide 2019 workshop "Evolutions of the Disciplinary Boundaries of Economics with the Other Sciences," Montreal (QC, Canada), 2527 June. It was partly based on a paper presented at the HOPE CONFERENCE "Becoming Applied: The Transformation of Economics," April 2016. We would like to thank the participants of both conferences and especially Marcel Boumans. We would also to thank Julien Dupont, Emmanuelle Kalfon and Ms. Anne Le Bihan of the "L'Ecume" bookshop of Groix.

2 PHARE/University Panthéon-Sorbonne, Maison des Sciences Economiques, 106-112 boulevard de l'Hôpital, F-75013 Paris

ariane.dupont-kieffer@univ-paris1.fr

${ }^{3}$ BETA- Université of Haute-Alsace, 2 rue des Frères Lumières, 68093 Mulhouse cedex. rivot@unistra.fr

${ }^{4}$ UPE/IFSTTAR/AME/DEST.

jean-loup.madre@,ifsttar.fr 


\section{Introduction}

After World War II, economic growth recovered, stimulated by public investments (especially infrastructure building). The car market developed rapidly, generating an exponential traffic growth: the number of vehicles/km per inhabitant was multiplied by 4 between the early $60 \mathrm{~s}$ and the mid-90s (BITRE, 2012). However, the pre-existing road network was too small to support both the economic and the population growth in the Western World: transport planning authorities and policy makers focused on extending the road network and its related efficiency. The road market partial equilibrium is identified with the road network equilibrium. The latter is given by the performance of the road network, i.e. the relation between the number of vehicles on the roads and the average speed on the network. Network performance is supposed to firstly estimate the number of vehicles on the road and secondly to manage the road demand in order to avoid congestion (Pigou, 1920). Road demand is related to two distinctive analyses: firstly, the complex issue of road demand estimation (the number of trips and number of vehicles circulating on a given network over a given geographical area)-which was the task of engineers, and secondly, the road demand management (how to allocate these flows of vehicles over the road network in order to avoid congestion, and over externalities, how to generate revenue in order to finance the building up and maintenance of road networks)-which was the task of economists. The network performance has been considered from an infrastructure-driven perspective since Dupuit's proposals (1844) regarding the collective utility gained from public roads were not to be found widely convincing, neither by his engineering colleagues nor the economists of the era. The infrastructure perspective adopted for road demand estimation built solid boundaries between engineering and economics.

The golden age of transport modelling began in the 1950s, and flourished in the United States in the 1960s where engineers faced major road construction needs. ${ }^{5}$ The key issue was to estimate traffic in order to adjust road networks accordingly. These so-called macro-models -like the micro-models used for traffic simulations- were developed by transport economists and engineers within a context in which transport policies were geared

\footnotetext{
${ }^{5}$ See Peterson 2020, especially Chapters 5 and 7, to understand the context and the role of the National Academies in promoting modelling and an engineering approach to road and highways.
} 
towards supporting a "car-oriented society," with roads seen as a key factor to boost economic growth. It might come as little surprise that an issue as complex as the estimation of road demand should, for years, have been tackled through an engineering approach in preference to an economic approach; and this, mostly for operational reasons.

Until the 1970s, we can say there had been a clear division of labor within the transport community between the engineers who were responsible for providing traffic flow estimates based on statistics, and the economists charged with managing the estimated flows. The two communities relied on distinct disciplinary approaches with few exchanges and no cross-fertilization between the two.

Engineers are in charge of the estimation of the number of trips over a distance and how these trips will be spread among the different networks. Economists are in charge of estimating the revenue generated by a network and how pricing can be used in order to reduce congestion and externalities generated by the considered network. Network performance can be improved by an engineering approach (building more roads, reducing parking places at destination, improving pavement in order to reduce road risk) in order to adapt the infrastructure to the estimated trips seen as vectors in a definite space. As shown by Lindsay (2006) and McDonald (2013), economists' contribution to road market equilibrium are related to the management network performance with the investigation of congestion prices and externalities. Key examples are then provided by the works of Pigou (1912, 1920), followed by Knight's (1924) reaction. While Pigou suggested regulating traffic through the implementation of a toll, Knight suggested to let the private sphere regulate traffic and reduce road congestion. By addressing the issue of traffic congestion in this way, Vickrey's aim was clearly to take into account the interactions between supply and demand. ${ }^{6}$ For him, the fare should not merely be seen as a tax, since in this analysis the time spent in transportation (especially congestion) is considered a legitimate component of the transportation cost. ${ }^{7}$

\footnotetext{
${ }^{6}$ Vickrey proposed an innovative approach of congestion pricing for the New York Subway in his study published in 1955 . Vickrey $(1952,1955)$ was motivated by analyzing the complexity of the decision-making process for a derived demand within the perspective of actual measurement, although transportation was one point in the "broad spectrum of his contributions" (Drèze, 1997, 6) in his analytical and methodological agenda.

7 Other significant contributions are worth mentioning. Buchanan $(1952,1956)$ revisited Pigouvian pricing to question its compatibility with social welfare. Later, Allais et al. (1967) investigated whether tolls would challenge or damage the process of the optimal allocation of resources.
} 
However, transportation economic analysis concerning the demand for transportation was based on the management of exogenous flows over a certain space, which had previously been assessed by engineers. It is in this specific context that we should understand the contributions of Daniel McFadden, recipient of the Nobel Prize in 2000 for his contributions on the conditional logit model, which allows the analysis of discrete choices, to the economic analysis of transportation demand. Whereas before McFadden's seminal 1974 paper in the Journal of Public Economics, the approach had been highly centralized and based on traffic, after this, an activity-based approach emerged that was based on mobility needs. McFadden wanted to shed light on the fact that people are, indeed, moving over a territory and that their trips can be seen as a vector from point A to B, that is to say from an important center of socio-economic activities to another attractive one. But to complement this engineering approach of population transfer to different points of the area, the trips correspond to a derived demand. He addresses these issues of the distribution of trips over a zone in terms of an indirect utility function and not in terms of distance and gravitation, as they had mostly been addressed beforehand by engineers.

The purpose of this paper is to investigate precisely how McFadden contributed to make the boundaries between engineering and economics permeable, and enhance a dialogue between engineers and economists. More specifically we show that on this occasion, the issue at hand was not the rise of an interdisciplinary approach to transportation thanks to crossfertilization but rather the incorporation of economic tools within engineering. To this extent, we address the topic of this special issue dedicated to the disciplinary boundaries of economics with the other sciences by showing how with McFadden economists pushed the boundaries of their discipline across engineering. In a first stage we present the state of transportation demand analysis and in particular the earlier contributions on demand specification prior to McFadden's 1974 paper. In a second stage, we argue that McFadden's contribution did indeed represent a milestone in road demand analysis by focusing on the determinants of travel behavior and of the indirect driving forces to transportation needs and modal choice. Doing so, he imported economic analysis in the engineers' model of road demand estimation: the motivation for moving was not anymore explained by a distance but by the derived demand for transportation. 


\section{Road demand analysis before McFadden}

After World War II, economic recovery was underpinned by public investments, particularly in infrastructure building. The car market expanded rapidly, generating exponential traffic growth, ${ }^{8}$ and the existing road network in the Western World proved far too small to support economic growth or the associated population growth. Transport planning authorities and policy makers accordingly focused on extending the road network and increasing its efficiency.

These engineers were trained in dedicated engineering schools, and we can mention two types of leading schools, the first one embedded in a multi-disciplinary academic environment as in the US with MIT and GeorgiaTech and the other one embedded in the training of civil servants with high levels skills in applied Mathematics and Physics, as in France with l'Ecole des Ponts et Chaussées and L'Ecole Nationale des Travaux Publics de l'Etat. These engineering schools were and still are very technically and operationally oriented. Even the management of road demand was favoring playing with the size of the road network over pricing, solutions analyzed by Alan Walters $(1961,1968){ }^{9}$

The awareness of this division of labor between engineers estimating the network equilibrium and economists focusing more on the management of road demand by pricing can explain Solow's urge to build bridges between the two communities. He indeed suggested in a letter to E. C. Brown, the head of the Economic Department at MIT ${ }^{10}$ to invite Alan Walters:

\footnotetext{
${ }^{8}$ The number of vehicles/km per inhabitant increased fourfold between the early $60 \mathrm{~s}$ and the mid-90s (BITRE, 2012).

${ }^{9}$ Even later, in the early 80s, Walters (1982) reduces transport externalities, its costs and pricing as the mean to manage road demand (and not to estimate it).

${ }^{10}$ As shown by Cherrier (2014), MIT was in the after WWII a specific environment with the rise of an economist community within an engineering school in the Boston area. We can then understand we can find some contributions of Samuelson (1952) whose paper has particularly been influential on Koopmans 's report of 1956, or Arrow to transportation economics without basing their research agenda on transportation issues. This intertwining and the influence of the MIT engineers in Local, National and Federal Agencies and also its influence on the different committees of the Transport Research Board (TRB) of the National Academies is an on-going research. The interaction between economists and engineers at MIT can, maybe, explained the willingness in the US, under the influence of the TRB, to undertake improvements of the analysis of decision-making process within the road demand estimation and analysis, especially after the work of Quandt and Baumol. (1966).
} 
"As you know, I have a particular interest in seeing the economics of transportation well-taught at M.I.T.”: I now have a fair acquaintance with the literature, and it seems quite clear to me that Alan Walters is the most interesting, able, and versatile person working on the subject. What is perhaps most attractive is the easy way he combines a clear grasp of the theoretical culture with a feeling for application, whether highway-planning in Africa or motor taxation in England (...) we would profit from having Walters here because his presence would be a major step toward making M.I.T. one of the leading centers of research in transportation economics in the world" (Robert Solow Papers, Box 52, folder "B: 5 of 7", Duke University). ${ }^{11}$

Bridging economics and engineering took place between 1965 and 1975, following debates on the linearity of the decentralized decision- making process. Intense discussions took place on the improvement of trip distributions, mainly on modal split and the understanding of trip determinants and road transport demand. The modeling then started to focus more on the utility functions and on the substitution rate between time and cost of transportation.

\section{II.1. The first contemporary economic contributions concerning road demand specification seen as a decisional process over time and space}

The report by the Cowles Commission in 1956, which included an introduction by Tjalling Koopmans, was a consequence of its participation in the RAND program. It became a key reference for the transport community, its multi-disciplinary approach forming the core of research 'in the field'.

It was edited by Koopmans, ${ }^{12}$ who had already investigated transportation issues in 1939. The report aims at tackling the complexity of transportation by distinguishing transport demand analysis per mode. The choice is to develop two types of models to assess travel demand, one for a decentralized system that is to say road and the other for a centralized system that is to say railway. In both cases the transport demand analysis is developed in

11 This letter was brought to our attention by Pedro Duarte during his stay at Duke in September 2016.

${ }^{12}$ Koopmans asked Vickrey to read and comment upon the entire manuscript of the report and his contribution as a referee and advisor is widely acknowledged. 
terms of network performance and traffic estimation. The introduction by Koopmans clearly elucidates to the audience what is at stake when assessing transport demand: the aim is the efficient use of transport infrastructure that means to estimate the $\operatorname{traffic}^{13}$ and 'traffic equilibrium'.

This Report shows the complex sociology of the transport community and how road transportation research gathers people coming from different environments and from different disciplines, as producers and users of knowledge. As underlined by Koopmans, the community, as the audience is acknowledged as coming from diverse horizons and as having ‘the problem solver dimension' for transportation analysis:

“ The exploratory studies presented in this report are addressed to analysts in various professions, including economists, traffic and railroad engineers, management scientists, operations researchers, and mathematicians who are interested in assessing capabilities and studying the efficient operation of transportation systems.” (Koopmans, 1956, xi)

Not only the audience is diverse but also the contributors as well as the references used to develop this study. The contributors, led by Koopmans, come from different backgrounds and Koopmans insisted on their complementarities. The main contributors are defined as mathematician economists like Martin Beckman, Christopher Winsten ${ }^{14}$ Marc Nerlove, Kirk Fox and Mc Guire. Koopmans underlined that the contributions were a combination of academic research contributions and discussions with operating authorities in the railway sector and the highway sector, not only from the Chicago area but also from Ohio. $^{15}$

Let's turn to the references supporting this understanding and measurement or both road demand and railway demand. Some are explicitly borrowed from outside the field of transportation, namely economic analysis to "help to balance inventory costs against losses

${ }^{13}$ The identity between traffic and transport demand is made again in the Report of Research Activities by the Cowles Foundation for Research in Economics at Yale University, July1, 1956-June 30, 1958, p.31 in the part "Special Publication".

${ }^{14}$ Koopmans explicitly mentioned his skills in probability theory.

${ }^{15}$ Are mentioned the Association of American Railways, the Car Service Division, the Potomac Yard, the Rock Island. 
from stock depletion" with the work of Arrow, Harris and Marschak in $1951^{16}$ and the work of Dvoretsky, Kiefer, and Wolfowitz in 1952. ${ }^{17}$ The other references are introduced to improve linear programming. The aim is to extend simple already developed models in transportation in order to take into account congestion, terminals and most of all routes. The references are borrowed from two types of fields: firstly from Mathematics with F.L. Hitchcock (work in transportation and published with the help of MIT in 1941) ${ }^{18}$ and L. Kantorovich $^{19}$ (in 1942 in Russia), and secondly linear programming carried out either by mathematicians for transportation issues with the work of Flood in $1953^{20}$ and $1954^{21}$ on tanker fleet problems for the army or by economists interested in "the relative costs of alternative possible changes in the ratio costs for freight rates formed in competitive market" (Koopmans, 1956, xii) as Koopmans did in 1947, or as Samuelson in 1952 for understanding " freight rates in relation to interregional prices and movements of goods" (ibid).

This handbook focused on road demand understood as traffic analysis along the engineering approach. But the Cowles Commission, with Koopmans, launched a rail and road traffic approach based on individual choices, which aimed at taking into account from the outset the heterogeneity of tastes and transportation attributes that might easily entail nonlinearity within the demand-function.

But, at that time, a competitive model imposed itself as the alpha and omega for the estimation of road demand and traffic equilibrium: the Four-Step Model developed in 1954 by Mitchell and Rapkin.

\section{II.2. Road demand analysis under the perspective of extending road networks over a certain area: the realm of engineers}

\footnotetext{
${ }^{16}$ Arrow, K., T.E. Harris, and J. Marschak. 1951. Optimal Inventory Policy, Econometrica, $19,250-272$.

${ }^{17}$ Dvoretsky, A., Kiefer, J., and J. Wolfowitz. 1952. The Inventory Problem, Econometrica, 20, 187-222, 450-456.

${ }^{18}$ Hitchcock, F.L.1941. The Distribution of a Product from Several Sources to Numerous Localities, Journal of Mathematics and Physics, (Massachussets Institute of Technology), 20, 224-230.

${ }^{19}$ Kantorovitch, L. 1942. On the Translocation of Masses, Doklady Akad, Nauk, SSSR, 37, 199-201.

${ }^{20}$ Flood, Merrill, M. 1953. On the Hitchcock Distribution Problem, Pacific Journal of Mathematics, 3, 369-396.

${ }^{21}$ Flood, Merrill, M. 1954. Applications of Transportation Theory to Scheduling a Military Tanker Fleet, Journal of the Operations Research Society, 2, 150-162.
} 
Since the 1950s, the United States had been developing seminal transport models in response to the urgent need to structure and manage a continuously expanding road network composed of highways and urban roads. The Detroit and Chicago Transportation Authorities sought modeling methodologies in order to estimate traffic and to build the related road infrastructure. The landmark proposal was the Four-Step Model (FSM) developed by Mitchell and Rapkin (1954), which incorporated traffic and road demand as well as its impact on land use through the building of road infrastructures. This model was an answer to concrete issues raised by politicians to do with congestion and the value of time. As also reflected in the work of Banzhaf (2017) regarding environmental economics and the question of the value of natural parks, or of Alacevich (2017) regarding development economics, the idea was to gather different analytical tools and methodologies in order to build a corpus or toolbox that would help operators to solve the issues they faced. The FSM model, inspired by Quesnay's input-output analysis, ${ }^{22}$ was developed further in order to take into account the substitution rate between time and money that broadly explains the modal choice within the demand function for transport. In the 1960s, the FSM was disseminated to the international transport community composed of both transport economists and planners, first in the UK and then in the rest of Europe, Australia, and the Commonwealth (Bates, 2000, Chapter 2).

\begin{abstract}
"The reason for the survival of this model form lies essentially in its logical appeal. The 4 stages model relates to: (1) trip generation (and attraction), (2) trip distribution, (3) modal split, and (4) assignment. Each stage addresses an intuitively reasonable question: how many travel movements will be made, where will they go, by what mode will the travel be carried out, and what route will be taken?" (Bates, 2000, 17)
\end{abstract}

The FSM can be considered as a sequential analysis of demand based on an OriginDestination matrix. A partial equilibrium is defined at each step, the general equilibrium being computed in the last step, this being the most interesting and complex part. The

\footnotetext{
${ }^{22}$ The input-output analysis relies on a zoning approach, as the final demands expressed in terms of out-going flows from one zone to another will be compensated by in-going trips. The zoning used in the FSM is administrative in the sense that it is the one in which all the socioeconomic data are collected. This zoning is built on former mobility patterns of the early $20^{\text {th }}$ century prior to the development of motorized vehicles and does not reflect the density of exchanges between two zones.
} 
assignment step (network approach) illustrates the focus placed on building and operating infrastructure. The FSM produces an aggregate view of disaggregated decisions. The idea is to convert units of individual/trips into vehicle/trips, under the assumption of constant cost matrices. The models of the distribution (or destination step) and of mode choices were crucial for gauging the quality of the interface between demand and supply.

The models of the distribution (or destination step) and of mode choices were crucial for the quality of the interface between demand and supply. The Matrix of flows can then be based on different models estimated for the purpose of each journey that the engineers acknowledged as relevant. The Matrix of flows reflects the weight of different sub-zones within the considered geographical areas. Potential flows being potential vectors of trips over the area are identified by describing:

- The characteristics ${ }^{23}$ of the origin/production of trips that is to say the characteristics of zone $i$; (a)

- The characteristics of the destination/attraction of trips that is to say the characteristics of zone $j$; (b)

Potential trips are determined by the socio-economic attractiveness of certain zones. The key feature of the FSM and its nickname of "gravitational model" comes from the way the engineers defined the travel cost between two areas. Indeed, the early FSM describes the functions $f$ as follows:

$$
f_{i j}=d_{i j}^{-2}
$$

where $d$ is the distance between the 2 zones. The engineers introduced there a gravity analogy with the Newtonian law, to give the main characteristics of the travel cost between two zones. The modal choice is simple: the user can choose between two modes, car or transit (bus or railway). In this simplified view of the transport system, the aggregate model can be written as:

$$
p_{m}[i j: k]=f\left(C_{i j m}^{k}, C_{i j(m)}^{k}\right)
$$

where $\mathrm{k}$ represents a share of the population, $i$ and $j$ the origin and destination, $m$ is the mode, $p_{m}[i j: k]$ is the share of the population using the mode $m$ between $i$ and $j$ and $C_{i j m}^{k}$ is the cost

\footnotetext{
${ }^{23}$ These characteristics are various and include macro- or meso-variables such as the attributes of the transportation system (road or transit services, reliability of transport services, frequency, etc.), and the attributes of the macro-environment (employment area characterized by the number of jobs and type of jobs, housing area, population density, facilities such as health centers, education centers, cultural activities, level of economic growth, etc.).
} 
of moving between $i$ and $j$ with mode $m$. The cost for each mode is put in perspective with the cost for travelling between $i$ and $j$ with the alternative mode, $C_{i j(m)}^{k}$. Most of the early FSM models relied, for this step, on assumptions on the proportion of people with car accessibility or transit accessibility without taking into account how the different patterns associated to the mode (combined with the trip purpose) were key drivers of individual decision-making for transportation services and goods. The last step is dedicated to computing and adjusting the performance of the transportation system. The supply in terms of infrastructure and operation is quite fixed in the short and mid-term and the reaction of the supply is measured in terms of speed congestion, parking issues, overcrowding in public transport modes. The assignment step is connecting the demand (pairs of zones characterized by residential patterns, job areas, public services) converted into traffic, and the supply (network capacities). The equilibrium estimation is very dependent on the nature of the interface between demand (pairs of Zones O-D) and supply (networks).

After running the FSM, and on the basis of the results of the assignment step, economists joined transportation demand analysis. Economic analyses can be developed once the engineers have estimated all the expected flows/trips (in passenger $/ \mathrm{km}$ or ton $/ \mathrm{km}$ ) that would spread on the different modal networks. Economic analysis was introduced in order to develop pricing recommendation of linear and nodal infrastructure to avoid congestion and reduce negative externalities, to tax revenue generated in real estate goods set up in the immediate proximity of transportation infrastructure. In his perspective - and contrary to the engineers' approach, tolls and pricing were not investigated as a means of funding the infrastructure building and maintenance but as a way "of bringing about the best utilization of the highway network" (Koopmans, 1956, xv). Contributions by Pigou (1920), Knight (1924), and Vickrey (1952) with his study on the optimal transit fare in New York City, even by H. S. Houthakker in his paper dated 1951 dealing with optimal electricity pricing ${ }^{24}$, addressed

${ }^{24}$ Marcel Boiteux (1922-) is a mathematician, and former student at the French Ecole Normale Supérieure, who was appointed at the Centre National de la Recherche Scientifique and assigned to the Allais seminar. In 1949 he was hired by Electricite de France to study optimal electricity pricing. His works are still considered as path-breaking contributions to the field of natural monopoly pricing. While addressing a different issue, namely optimal pricing in the case of peaks in electricity demand, Boiteux ([1949] 1960) also contributed to the field that interests us here. ${ }^{24}$ In a path-breaking contribution that was the first to formally analyze the issue of optimal electricity pricing, Boiteux showed that a social planner should charge for electricity at the marginal cost. This recommendation derived from Boiteux's formal demonstration that any network industry should charge at marginal cost in case of peaks in demand. It should be noted that Boiteux was clearly not addressing the issue of the choice 
the issue of network congestion (avoiding the congestion level that transforms a network from a public good status to a common good one). ${ }^{25}$

One other important part of transportation economics related to network analysis is the optimal allocation of the use of the networks and defined slots to different operators (a central one or to a bundle of competitors). ${ }^{26}$

The early FSM robustness and its rather reliable predictions in terms of flows and the performance of transport networks help to explain its success in the mid-sixties. The FSM provided clear guidance for transport infrastructure policies and its outcomes were solidly based on engineering:

"Travel Demand forecasting has long been the province of Transportation engineers, who have built up over the years considerable empirical wisdom and a repertory of largely ad hoc models which have proved successful in various applications. The contribution of psychologists and economists to forecasting methodology has been limited." (McFadden 1974, 303)

Even if economist' contribution was limited as they started to work once the FSM was run, they raised the awareness of transport engineers that transportation demand cannot ignore that different patterns associated to the mode (price, reliability, speed, etc. combined with the trip purpose) were key drivers of individual decision-making in the transportation of services and goods. That is, two main shortcomings were associated with the FSM.

The first identified weakness was the very thing that was claimed to be the key asset of the model itself, in which transportation utility is conflated with distance $\left(f_{i j}=d_{i j}{ }^{-2}\right)$. By reducing transport costs to a 'distance' factor, the complexity of the individual choice travelling to a given destination, which is a derived demand, was not taken into account: the

whether or not to consume electricity; he was concerned primarily with the issue of optimal pricing with regard to a demand that was exogenously determined.

Since in his argument in favor of congestion pricing he called for increasing fares at peak times, Vickrey (1955) can be seen as following in the footsteps of Boiteux.

${ }^{25}$ Another important part of transportation economics related to network analysis was the optimal allocation of the networks use as to say the allocation of slots to a central operator or to a bundle of competitors. As shown by Sorencik (2017), most of the debates, especially in operating airplanes, focused on the need to introduce more competition in the operation of transport networks. 
aggregated approach ignores the heterogeneity of tastes and motives among individuals, as well as the various preferences of an individual according to the trip purpose, the time of day, etc.

The second identified key weakness was the modal choice step. These models used were highly aggregated data in order to explain individual decision-making processes about trip generation and modal choice between two modes, a private mode such as car, and a public mode such as bus or railway transit. Such an approach failed to take into account modal choice and possible shift between car and transit, generated by pricing and fare policies.

\section{Economists departing from the FSM in road demand analysis.}

Between 1965 and 1975, intense discussions among engineers but also among economists took place regarding the improvement of trips distribution (step 2) and about the modal split (step 3) in order to get a better understanding of trip determinants and of road transport demand. The first point of contention was the sequence of the decision-making and the order in which the distribution and the modal choice steps were to be considered; this appeared to be a kind of chicken-and-egg issue. On the one hand, the distribution depends on modal choice, mode availability, and cost; on the other hand the modal split is conditional to destination and the purpose at destination.

The engineering approach to transportation needs ignored the travelling cost characteristics between the 2 zones - transport expenditure being of two kinds, money and time. ${ }^{27}$ Reactions to changes in transport expenditures vary accordingly with the trip circumstances, but also differ from one individual to another, but also for the same individual according to the trip purpose, which can explain the modal shift. The modelling then started to focus more on utility functions and on the substitution rate between time and transportation costs. These issues inevitably attracted the economists' interest.

\section{III.1. The first contemporary economic alternative to the FSM about demand specification before McFadden (1974)}

\footnotetext{
27 Time is converted to money units by means of the value of time-savings. The latter is very dependant of the level of income of the considered user.
} 
The first explicit criticism of the FSM came in 1966 from Quandt and Baumol, two economists interested in the decision-making process for demand (Quandt and Baumol, 1966, 13), although their attention was clearly more focused on the difficulties of measuring travel demand in a context of limited data. ${ }^{28}$ In short, Quandt and Baumol criticized two characteristics of the FSM - its method of data collection (using macro data to set the assumptions to frame individual decision-making process) and the need to properly measure preferences. Their main innovation was to develop instead their own concept of the 'abstract mode', according to which transportation possesses many attributes that cannot simply be conflated with distance. While they do acknowledge the spatial dimension of travel issues, they focused on the analysis of travel behavior and insisted on the need to understand the motivation for a trip and for choice of mode. To this end, their concept of the abstract mode broke with the traditional approach to modes developed by the engineers, ${ }^{29}$ allowing the comparison of different modes of transportation and the analysis of how modes compete with one another. The genuine modes are hereafter compared to the abstract mode thus defined.

Their proposal allows to compare modes of transportation and to see how far modes compete with one another: "the abstract mode approach permits meaningful comparisons of travel behavior along different arcs of transportation networks that might otherwise not be possible" (ibid. 25). By doing so, they put modal choice at the same level as trip generation, and focused on the two dimensions of travel cost, that is to say money and time. Enlarging travel demand estimation to the travel behaviour perspective forced to investigate offsets made by individuals between travel time and travel costs.

In their view, transport demand analysis should turn to economics, psychology, and sociology in order to investigate travel behavior. However, Quandt and Baumol's (1966) proposal entails that differences between centralized and decentralized modes should be overcome: although they did not aim at tearing down the barriers between modes, they proposed instead to develop a benchmark mode to take into account any trip in order to understand why people move. Even if "the abstract mode approach permits meaningful

\footnotetext{
28 "The variety of techniques one encounters in the field of travel demand estimation is at least partly a result of the scarcity and heterogeneity of the data. Studies which are intended to describe and predict behaviour on some particular geographic area may not be able to utilize the same types of data as studies referring to some other area [...]. Clearly, the larger the geographic area which must be encompassed by a model, the less likely it is that required data of uniform quality can be found" (Quandt and Baumol, 1966, 13).

${ }^{29}$ The abstract mode works on the idea that the user is selecting a certain number of relative characteristics in the abstract bundle "travel" in order to reach a certain destination according to the purpose of the trip.
} 
comparisons of travel behavior permits travel by different modes to be kept separate" (ibid. $25)$, and can be used to estimate the total travel demand.

As a matter of fact, the paper had unfortunately little impact on the community of transport engineers in charge of estimating the travel demand. We can assume that the transport community was not ready for both investigation of travel behaviour and trip purposes as well as for an abandonment of compartmentalization of transportation issues per mode.

\section{2. McFadden 1974: A milestone in transportation demand analysis}

As we have noted, the main weakness of the FSM was its inability to provide insights into the structure of the decision-making process for individual travel behavior. While the gravitational and aggregate approach proved helpful and robust in the prediction of aggregate flows on road and transit networks, the model stood to be improved by a deeper understanding of the drivers of travel (i.e. destination and modal choice). On this basis, the central interest of a new generation of economists and engineers in the 1970s was to gain better knowledge of travel behavior. In the early 1970s, McFadden became interested in this issue with the support of the National Science Foundation and the Department of Transportation for the San Francisco Bay Area.

First, on the theoretical side, McFadden's first innovation is encapsulated in his focus on a decentralized approach that accounts for heterogeneity in tastes and preferences. McFadden's contribution to discrete choice methods was of a general nature. As underlined by Manski $(2001,218)$, his main theoretical contribution was the introduction of a joint analysis of individual decisions and discrete choices. His use of transportation economics as case studies in the application of his method dramatically modified the field of transportation economics. Indeed, McFadden (1974) and Domencich and McFadden (1974) explored three distinct issues when estimating urban travel demand: (i) how to measure unobservable heterogeneous tastes in a utility function (the utility of a good characterized by a range of inter-related attributes); (ii) how to measure the fact that the choice relies on a dynamic and sequential decision-making process feeding into the utility function; and (iii) how to shift from individual preferences to distributions of preferences.

They proposed an extension of the traditional utility-maximization framework to discrete choice analysis, as a way to improve the estimation of demand functions by 
integrating mobility patterns. The issue at stake was to arbitrate between getting a more accurate shape for the demand function and adding more relevant explanatory variables. The work of Diamond (1971), later developed in Domencich and McFadden (1974), proposed to estimate the parameters of the utility function by linear logit models with individual or discrete data. The shift was favored by innovative works on discrete choices such as Finney's book of 1947, the Probit modelling developed by Warner (1962), and the Logit modelling advanced by Rassam et al. (1970).

McFadden's second contribution, on the econometric side, was the development of the Random Utility Model (RUM) as a means to handle heterogeneous tastes and preferences. Following Quandt and Baumol (1966), McFadden focused on the relation between aggregated demand and individual demand while taking into account. His answer was to posit and test the RUM:

$$
x_{t}=h\left(B_{t} ; \bar{\rho}\right)+\varepsilon_{t}
$$

where the individual demand for transportation $x_{t}$ is determined by his budget for transportation $B_{t}$ and his/her individual tastes $\bar{\rho}$ (the latter being both demographic observable variables as age, sex, education and unobservable variables as experience, childhood) and $\varepsilon$ is an unobserved random term distributed independently of $B_{t}$. The individual has a utility function $u=U(x, \rho)$ which is maximized under a budget constraint $B_{t}$ and for a set of demand $x_{t}$.

McFadden assumed that "the cross-section of consumers has observed demands which are distributed randomly about the exact values $x$ for some common or representative tastes $\bar{\rho}$ " (McFadden, 1974, 308). The RUM accounts for changes in individual tastes that might affect the aggregate demand, especially when the commodity attributes are heterogeneous and unobservable:

"Systematic variations in the aggregate demand for the lumpy commodity are all due to shifts at the extensive margin where the individuals are switching from one alternative to another, and not at the intensive margin as in the divisible commodity, identical individual case.” (McFadden, 1974, 309)

His proposal was to capture the effects of individual heterogeneous tastes in the structure of the error term. Many dimensions (mode availability, trip purpose, destination, etc.) related to the short-term (e.g., an urgent need to go to the doctor) and to the long-term 
(e.g., car ownership) influence the decisions underpinning travel demand. The multidimensional context calls for the development of a joint analysis in order to understand how transportation actually functions: "A successful behavioural theory should not only parallel the individual decision tree, but should exploit the separability of decisions implicit in this tree to make empirical analysis practical" (McFadden, 1974, 314).

To support these econometric innovations, he developed an empirical approach based on a combination of micro and macro data. McFadden gathered socio-demographic information such as gender, age, size of the households, years of education, etc. and data from the census (population, age, gender, car ownership and buses) as the FSM used too. In addition, interviews conducted in the San Francisco Bay Area, with the aim of improving the cost-benefit analysis (McFadden, 1974, 316). Due to limited resources, he was able to conduct only 213 interviews with Bay Area residents before (1973) and after (1975) the opening of the new Bay Area Transit System, seeking to examine the factors driving their choice of travel mode for commuting (ibid.). Questions were asked on the type of job and on the flexibility of working days, the obligation to have a second job, the driving license, on the type of dwelling (number of rooms), on the level of income.

A key issue was of course the definition and the computation of travel cost. McFadden then computed costs in combining time and money as e.g. "bus transfer time times wage" or "car-bus on-vehicle times post-tax wage, in min. per 1-way x \$ per hour". He based the value of time on the means of wage after tax for the sample. Yet, the most innovative aspect relies on the investigation of the motives of travelling and modal choice. Interviews went further into qualitative aspects of what happened during travelling such as: "I become angry in traffic jam" or "enjoy riding distances with the family", "fast freeway driving makes me nervous", "poor bus service is a problem", "bus drivers are polite". Table 3 (McFadden, $1974,322)$ is an attempt at identifying the correlations of unexplained residuals in binary logit analysis with candidate explanatory variables. He concluded "there is little relation between behavior and attitudes that might influences by a campaign publicizing the attributes of transit" (McFadden, 1974, 323). Even so, it is obvious that McFadden wanted to investigate the relation between travel behaviour and attitudes, and departed from the FSM that reduces travel behaviour to a distance. Transport demand analysis based on the FSM turned later into another way to investigate the generation of trips, this time by including the trip motivations directly into the model alongside the price of the trip. 
Especially through his interviews, McFadden explained his will to investigate the relation between travel behavior and attitudes and also to overcome the FSM's reduction of travel behavior and of distance. He ended by attracting the engineers' attention on motives behind trips as well as the patterns in travel behavior. To this extent, by incorporating economic concepts and reasoning, McFadden's contributed in 1974 to make the boundaries between engineering and economics more permeable. The motivation of trips was from the outset incorporated in the analysis of transportation modes. Users of road networks were henceforth considered as individual economic agents who maximize their own individual utility function and arbitrate accordingly between several modes of transportation for which distance was far from the only decision variable.

Retrospectively, McFadden describes his contribution as the "New Science of Pleasure" $(2013,1)$, i.e. as a "behavioral revaluation" exploring "expansions of neoclassical demand measurement, particularly to the subjects of choice in non-linear and discrete budget sets, and finally to new frontiers of measurement shared by economics and other disciplines cognitive psychology, anthropology, and neurology" (Ibid.).

\section{Concluding remarks: Transportation demand analysis after McFadden 1974}

From the 1950s to the present, road demand models have turned from the analysis of transport needs for infrastructure building, based on cross-cutting models (generation and distribution of traffic, modal split and traffic assignment, and even logistic models for freight deliveries) to the analysis of mobility needs and the articulation of transportation with the planned activities of the individual (e.g., activity-based modelling), based on longitudinal models. In this perspective, McFadden's 1974 paper should be seen as a milestone in the development of transportation analysis demand. Thanks to McFadden, economists were henceforth able to apply the classical theory of consumer to the issue of discrete choice, and to account for the heterogeneity of individual demands in their estimation of the shape of transport demand curves. So McFadden (1974) pushed the boundaries of economic analysis even further into the realm of the engineers with the development of the Generalized Cost, combining time and money, as the key tool at step 3 of the FSM instead of distance. 
Yet, after McFadden's (1974) contribution, boundaries shifted again. With economics fully integrated into engineering through the boom of the activity-based approach, ${ }^{30}$ road demand analysis departed from economics and engineering with geographers and urban planners. In the 1970s, important contributions to the debate on the concept of distance also stemmed from the field of geography, recalling Fernand Braudel's ideas (1949). ${ }^{31}$ The most influential criticisms of the traffic approach to road demand in the 1970s came specifically from the group nowadays named the "Transition Mobility," whose ideas were grounded in the pioneering 1971 work of the geographer Wilbur Zelinsky. Zelinsky (1971) associated his analysis of mobility with the definition of the transition dynamics that would be at stake in any society. By combining geography and demography to investigate the spatial structuration of economic and social activities, he linked types of mobility to different stages of modern "development" and economic growth. He questioned the use of "distance" in the FSM, pointing out instead that demography determines and frames the level and types of activities, as well as individual trips and flows on territories. ${ }^{32}$

In recent decades a remarkable shift of emphasis has taken place in transportation analysis, from an engineering-based approach to a pluri-disciplinary approach of transportation service. With the merging of engineering sciences, economic analysis and geography, a shift has occurred from an analysis of infrastructure building to an analysis much more eclectic, which now considers a large variety of attributes.

30 "The ABA [Activity Based Analysis] was born of the landmark study of Mitchell and Rapkin (1954). ABA modellers were interested in developing 'a transportation model that focused on travel only (the who, what, where, and how many of trips versus the why of activities), and the link between activities and travel was reflected in trip generation' (McNally, 2000, 56). But it is only after more than 15 years of investigation that modellers were able to provide an achieved ABA model with Ben-Akhiva and al. (1996).

$31 \leq \mathrm{http}$ ://fr.forumviesmobiles.org/caletrio/blog/2015/12/07/braudel-precurseur-des-etudessur-mobilite-3049> Blog of Javier Caletrío, Centre for Mobilities Research, Lancaster University.

32 Transport modelers were increasingly attracted by contributions, especially those of Hägerstrand (1970), who turned time and geographic patterns into systems of constraints on activity participation in time-space, of Chapin (1974), who anchored travel patterns in a bidimensional approach in terms of time and space, and of Fried, Havens, and Thall (1977), who related travel needs to social structure and activity participation. 


\section{REFERENCES}

Allais, M.F.C., Del Viscovo, M., de la Vinelle, L.D. et al., 1967. Options in transport Tariff Policy (report by a Committee of Independent Experts to the Commission of the European Economic Community). Brussels. European Commission.

Alacevich, M., 2017. Theory and Practice in Development Economics, History of Political Economy, 49 (Supplement): 264-291.

Banzhaf, S., 2017. Constructing markets: Environmental Economics and the Contingent Valuation Controversy. History of Political Economy, 49 (Supplement): 213-239.

Bates, J., 2000. History of demand modelling in Hensher, D.A., and K.J. Button (eds). 2000. Handbook of Transport Modelling, Pergamon, Elsevier Science, Ltd, 11-33.

Ben-Akiva, M., Bowman, J., and Gopinath, D. .1996. Travel demand model system for the information era, Transportation (23), 241-266.

BITRE, (Bureau of Infrastructure, Transport and Regional Economics), 2012. Traffic growth: Modelling a global phenomenon. Rapport 128, Bureau of Infrastructure, Transport and Regional Economics (Australia).

Boiteux, M. 1949, La tarification des demandes en point: application de la théorie de la vente au cô̂t marginal. Revue Générale de l'électricité 58 (August): Journal of Business 33 (1960): 157-79.

Braudel, F., 1949, La Méditerranée et le monde méditerranéen à l'époque de Philippe II, Armand Colin. Réed. At LGF in 1993.

Buchanan, J. M., 1952. The pricing of highway services, National Tax Journal, 5, 97-106.

Buchanan, J. M., 1956. Private car ownership and common usage: the road case re-examined, Southern Economic Journal, 22, 305-16.

Chapin, F.S., 1974. Human Activity Patterns in the City, New York: Wiley.

Cherrier, B., 2014. Towards a History of Economics at M.I.T., 1940-72, History of Political Economy, 46 (Supplement): 15-44.

Diamond, P., 1971. A model of price adjustment, Journal of Economic Theory, 3(2), 156-168, June.

Domencich, T. and McFadden, D.L., 1974. Urban Travel Demand: A Behavioral Analysis, Charles River Associates, North -Holland Publishing Co. Reprinted in 1996.

Drèze, J., 1997. "Research and Development in Public Economics: William Vickrey's Inventive Quest of Efficiency.” Scandinavian Journal of Economics 99, 179-198.

Dupuit, A.J. E.J. 1844. De la mesure de l'utilité des travaux publics. Annales des Ponts et Chaussées, Mémoires et Documents, 8, 332-75. 
Finney, D.J., 1947. Probit Analysis. (1st edition), Cambridge University Press, Cambridge, UK.

Fried, M., Havens, J. and M. Thall, 1977. Travel Behavior-a synthesized theory, NCHRP, Transportation research Board, Washington D.C., Final Report.

Hägerstrand, T., 1970. What about people in regional science? Papers of the Regional Science Association, 24, 7-21.

Houthakker, H. S., 1951. Electricity Tariffs in Theory and Practice, Economic Journal, 61, 125.

Knight, F. H., 1924. "Some Fallacies in the Interpretation of Social Cost." Quarterly Journal of Economics, 38 (3), 582-606.

Koopmans, T.C., 1947. Optimum Utilization of the Transportation System, Proceedings of the International Statistical Conferences, 5, 136-146. Reprinted as supplement to Econometrica, 17, (1949), 136-146.

Koopmans, T.C., 1956. Introduction in Beckman, M., McGuire, C. B. and C. B. Winsten, Studies in the Economics of Transportation, Published for the Cowles Commission for Research in Economics by Yale University Press: New Haven, London: Geoffrey Cumberlege, Oxford University Press.

Lindsay, R. 2006. Do Economists Reach A Conclusion on Road Pricing? The Intellectual History of an Idea. Econ Journal Watch, 3(2), 292-379, May.

Manski, C.F., 2001. Daniel McFadden and the Econometric Analysis of Discrete Choice, The Scandinavian Journal of Economics, 103(2), 217-229.

McDonald, J.F., 2013. Pigou, Knight, Diminishing returns, and optimal pigouvian congestion tolls, Journal of the History of Economic Thought, 35, 353-371.

McFadden, D.L., 1974. The Measurement of Urban Travel Demand, Journal of Public Economics, 3, 303-328.

McFadden, D.L., 2013. The New Science of Pleasure, NBER Working Paper 18687, National Bureau of Economic Research, January. (Initial version presented at the Frisch Lecture, Econometric Society World Congress, London, 2005).

McNally, M.G. 2000. The activity-based approach, in Hensher, D.A., and K.J. Button (eds), 2000. Handbook of Transport Modelling, Pergamon, Elsevier Science, Ltd, 53-69.

Mitchell, R.B. and C. Rapkin., 1954. Urban Traffic: A function of Land Use. New York: Columbia University Press.

Peterson, S. J., 2020. The Transportation Research Board 1920-2020, Everyone interested is invited. Washington, DC: The National Academies Press. 
Pigou, A.C., 1912. Wealth and Welfare, London, Macmillan.

Pigou, A.C., 1920. The Economics of Welfare. London: Macmillan and Co.

Quandt, R.E. and W.J. Baumol., 1966. The demand for abstract transport modes :theory and measurement, Journal of Regional Science, 6 (2), 13-26.

Rassam, P.R., Ellis, R.H. and J. C. Bennett. 1970. The N-dimensional logit model: development and application, Peat, Marwick, Mitchell and Co, Washington.

Samuelson, P. A., 1952. Spatial Price Equilibrium and Linear Programming, American Economic Review, 42, 283-303.

Solow, R., Robert M. Solow Papers, David M. Rubenstein Rare Book \& Manuscript Library, Duke University. (1960-2013).

Svorenčik, A., 2017. Allocating Airport Slots: The History of Early Applied Experimental Research. History of Political Economy, 49 (Supplement): 240-263.

Vickrey, W.S., 1952. The Revision of the Rapid Transit Fare Structure of the City of New York, Finance Project, Mayor's Committee on Management Survey of the City of New York, Technical Monograph No. 3, New York, February.

Vickrey, W.S., 1955. A Proposal for Revising New York's Subway Fare Structure, Journal of the Operations Research Society of America, 3(1), 277-306.

Walters, A., 1961. The Theory and Measurement of Private and Social Costs of Highway Congestion, Econometrica, 29, (4), 676-99.

Walters, A., 1968. The Economics of Road User Charges, World Bank Staff Occasional Papers Number 5, Baltimore, MD: The Johns Hopkins University Press.

Walters, A., 1982. Externalities in Urban Buses, Journal of Urban Economics, 11, 60-72.

Warner, S., 1962. Stochastic Choice of Mode in Urban Travel;A Study in Binary Choice, Evenston: Northwestern University Press.

Zelinsky, W., 1971. The Hypothesis of the Mobility Transition," Geographical Review, 61(2), 219-24. 